\title{
ENSINO SUPERIOR NO BRASIL: DIFICULDADES NO ACESSO E ENSINO PÚBLICO PARA POUCOS
}

\author{
Gabriel Rodrigues Oliveira
}

\begin{abstract}
RESUMO
O presente artigo busca traçar um panorama geral sobre a oferta de ensino superior no Brasil. A partir da análise de dados oficiais e da revisão de literatura sobre o assunto, questiona-se qual parcela da população mais usufrui deste aumento de vagas. Primeiramente foi analisado o perfil do jovem brasileiro matriculado no ensino superior. Após isso, foi separado o ensino superior público do privado, observando se o perfil nestes dois universos é diferente. Também foi elaborado um questionário público, para analisarmos de modo mais qualitativo o perfil dos universitários. Conclui-se que, mesmo com os avanços na oferta de disciplinas, o ensino superior ainda é anormal na vida dos jovens brasileiros. E quanto menor for o nível econômico do jovem, mais anormal se torna.
\end{abstract}

Palavras-chave: Ensino Superior; Brasil; Acesso; Dificuldades.

\begin{abstract}
The present article seeks to give an overview of the offer of higher education in Brazil. Based on the analysis of official data and the literature review on the subject, it is questioned which portion of the population most benefits from this increase in vacancies. First, the profile of the young Brazilian enrolled in higher education was analyzed. After this, public higher education was separated from the private, observing if the profile in these two universes is different. A public questionnaire was also prepared to analyze the profile of university students in a more qualitative way. It is concluded that, even with the advances in the offer of courses, higher education is still abnormal in the life of Brazilian youth. And the younger the economic level of the young, the more abnormal it becomes.
\end{abstract}

Keywords: Higher education; Brazil; Access; Difficulties. 


\section{Introdução}

Uma das principais questões abordadas no cenário político do Brasil é a Educação. Neste campo, o Ensino Superior ainda é tratado como privilégio por grande parte da população brasileira - ainda mais se estivermos falando do Ensino Superior público. A partir dos anos 90 houve um crescente foco nas políticas de acesso ao Ensino Superior (ANDRADE, 2012). Podemos citar diversos tipos de políticas afirmativas que realmente trouxeram resultados (cotas em Universidade Publica para negros e aqueles que cursaram o ensino médio em escolas públicas, por exemplo). Porém, muitas vezes o resultado final parece mais bonito do que quando analisamos friamente os números. Este artigo tem como objetivo mostrar, com base em pesquisa bibliográfica, como a política de acesso ao Ensino Superior ainda é defasada, mesmo com os avanços nas últimas décadas. E como, após análise dos dados disponíveis, a grande maioria das vagas em Universidade Pública acaba nas mãos dos brasileiros brancos de classe alta, e que brasileiros não brancos (negros, pardos e indígenas) muitas vezes de classe média/baixa e que cursaram por completo o ensino em escolas públicas, acabam ficando com as vagas em Universidades Privadas, tendo que utilizar novamente políticas de financiamento estudantil para viabilizar estudos.

\section{Qual é o perfil do universitário brasileiro?}

De forma a gerar dados comparáveis com a teoria, foi elaborado um questionário (Anexo I) destinado aos estudantes universitários brasileiros. Participaram desta pesquisa 60 alunos. O objetivo deste questionário é montar um perfil base do estudante universitário - $\mathrm{E}$ entre as questões, abordadas estão: a renda média; etnia; local onde cursou o ensino médio; e se o aluno teve suas expectativas confirmadas com o curso.

\section{Panorama geral do ensino superior no Brasil}

A partir dos anos 90, a oferta de educação superior brasileira se alterou significativamente. De acordo com o PNAD (2009), 19\% brasileiros na faixa etária dos 18 aos 24 anos estão matriculados no Ensino Superior. Este número pode ser visto de forma positiva para os que avaliam bem a política de ensino superior brasileira. Porém, quando comparado com países desenvolvidos, é um número baixo, já que nos EUA $45 \%$ dos jovens estão matriculados, e na Coréia do Sul 69\% (NCES, 2010). 
Mas afinal, quem seriam esses $19 \%$ dos jovens que estão matriculados? E quem, por outro lado, seriam os outros $81 \%$ sem acesso? Uma pesquisa analisou os perfis socioeconômicos, cor autodeclarada e escolaridade dos jovens (ANDRADE, 2012).

Segundo a autora, quase metade dos jovens no Brasil (48\%) não concluíram nem o Ensino Médio, parando após concluir o Ensino Fundamental (mais 21\% nem o Fundamental concluíram).

A referida evolução a partir da década de 90, defendida por alguns pesquisadores, realmente aconteceu, mas qual tem sido a parcela da sociedade brasileira que realmente se viu beneficiada?

Segundo a pesquisa de Andrade (2012), a partir de dados da PNAD/IBGE de 2009, ao analisarmos a renda familiar, no campo dos mais pobres, apenas 3\% chegaram ao Ensino Superior. Comparativamente com o quintil mais rico, $60 \%$ tiveram acesso ao Ensino Superior.

Quando analisamos os dados pela cor autodeclarada, 2,9 milhões de brancos tiveram acesso ao ensino superior, ao passo que somente 1,3 milhões de não-brancos (negros, pardos e indígenas) tiveram acesso, com 3,3 milhões sem concluir o ensino fundamental sequer.

A diferença percentual, quando se analisa a variável cor autodeclarada, é menor do que quando se analisa a renda. Nas faixas de menores rendas existe, também, um fator cumulativo: jovens entram atrasado no ensino para ajudar os pais e mães no trabalho. E muitos abandonam no meio, preferindo voltar a trabalhar, mesmo que seja para ganhar relativamente pouco.

Além disso, é fato que a população não-branca está concentrada nas faixas de menores rendas no Brasil, em média. Assim, Andrade (2012) destaca que o foco das políticas afirmativas deveria ser a Renda Familiar (deixando claro que isto não significa acabar com as políticas envolvendo etnia).

\section{Universidade pública $\mathrm{x}$ universidade privada}

Quando analisado especificamente a situação em Universidades Públicas, também é visível o aumento de vagas a partir dos anos 90 . Porém, apenas $26 \%$ das matrículas está no setor público, contra 74\% do setor privado (BARROS, 2015). A autora destaca que o motivo principal desta diferença é a facilidade da criação de faculdades privadas voltadas ao lucro.

E, desta porcentagem de matrículas no setor público, a maioria é feita por aqueles que cursaram o ensino básico privado - e, consequentemente, vêm de quintis mais ricos da 
população. Segundo Knobel (2014), analisando especificamente o caso da Unicamp, do total de estudantes que prestaram vestibular, $70 \%$ viam de escolas privadas, contra $30 \%$ de escolas públicas.

Um alto número de alunos que saíram de classes baixas nem tentam seu ingresso em Universidades Públicas. Muitos já optam por políticas como o Fies, e ingressam no setor privado. O sentimento de que não é possível frequentar Universidades públicas está intrínseco em boa parte dos estudantes de menor renda. (ALMEIDA, 2007).

As políticas afirmativas se tornam fator preponderante aqui, já que permitem que não haja uma diferença drástica nos matriculados no setor público. As Universidades Federais são exemplo, onde $43 \%$ das matrículas são de alunos da classe C, D e E (MEC, 2015).

\section{Perfil do jovem}

Foi realizada uma pesquisa online (resultados no Anexo II) com jovens matriculados no Ensino Superior. O perfil da referida pesquisa é eminentemente qualitativo, por contraposição à abordagem quantitativa, contendo algumas perguntas-chave.

A pesquisa tem como objetivo comparar seus resultados com os dados analisados anteriormente.

Ao final da pesquisa, obteve-se a participação de 60 jovens. A partir desta pesquisa foi chegado ao resultado a seguir: $59,5 \%$ dos jovens se autodeclararam brancos, contra $40,5 \%$ de não-brancos; Mais da metade $(70,2 \%)$ declaram ter renda média/alta.

Um dos dados mais interessantes é o que se segue: $67,6 \%$ concluíram o ensino médio em escolas públicas, ao passo que $78,4 \%$ se graduaram no Ensino particular. Isto ajuda a exemplificar como as políticas públicas são importantes, já que, um desequilíbrio a ser corrigido, é o de que maioria das vagas em universidades públicas acaba alocada para jovens que tiveram um estudo de melhor qualidade em escolas particulares.

Quando perguntado o motivo que os levou a entrar naquele curso, a resposta que mais se repetiu ateve-se ao âmbito profissional: ter um bom currículo, e se firmar no mercado de trabalho. Poucas foram as respostas onde a afinidade com o curso preponderava. A pressão social e familiar de hoje faz com que muitos jovens se matriculem em cursos superiores sem antes saber se aquilo é o que ele realmente quer. Pode levar a um abandono do curso, e forma profissionais insatisfeitos. Por exemplo, $41 \%$ das pessoas disseram não ter suas expectativas com o curso confirmadas, ou apenas confirmadas em partes. A maioria das respostas mostrava que o aluno não tem grande afinidade com as matérias, que não conhecia o currículo do curso. 
O maior ponto positivo apresentado foi de ter aumentado seu conhecimento do mundo, o desenvolvimento de um pensamento mais crítico. Como ponto negativo, foi a qualidade da grade de ensino, ou a má didática de alguns professores.

\section{Conclusão}

Conclui-se que houve um crescimento absoluto e percentual na oferta de Ensino Superior no Brasil, porém ainda há tópicos a serem discutidos e aprimorados. Um deles seria a melhor forma de promover as políticas afirmativas que, como visto (KNOBEL, 2014), são necessárias - principalmente em relação ao fator "renda familiar", pois o abismo entre o acesso dos mais ricos e dos mais pobres é altíssimo. Um exemplo positivo seria o que ocorre nas Universidades Federais, que reservam parte de suas vagas para ações afirmativas.

Também se vê como necessário iniciar uma discussão sobre como incentivar o aluno, que acaba de sair do ensino básico público, a buscar seu ingresso em Universidades Públicas. Muitas vezes o senso comum que se observa é o de que o ensino gratuito não é para os mais pobres (ALMEIDA, 2007), e por isso já partem para o setor privado, utilizando as políticas de financiamento. Isto nos remete ao ensino básico, que deve passar por mudanças para melhor capacitar os alunos.

A aplicação de questionário confirmou algumas questões apresentadas, principalmente da renda familiar, e de que aqueles que cursaram o ensino básico em escolas públicas se matriculam em grande maioria nas universidades públicas. 


\section{ANEXO I - QUESTIONÁRIO ONLINE}

Declara-se

Branco(a)

Pardo(a)

Negro(a)

Indígena

Oriental

Faixa salarial da família (em salários mínimos - R\$ 937,00)

Até 1

De 1 a 3

De 3 a 5

Mais de 5

Sua formação no Ensino médio foi, em sua grande maioria:

Ensino Público

Ensino Privado

Ensino Técnico

Sua graduação foi em:

Universidade Pública

Universidade Privada

Motivo que o levou a entrar no curso:

Suas expectativas sobre o curso se confirmaram?

Sim

Não

Em partes

Se não se confirmaram (ou em partes), o que houve?

Qual foi o maior ponto positivo de sua experiência com o Ensino Superior?

Qual foi o maior ponto negativo de sua experiência com o Ensino Superior? 


\section{ANEXO 2 - RESULTADO DO QUESTIONÁRIO ONLINE}

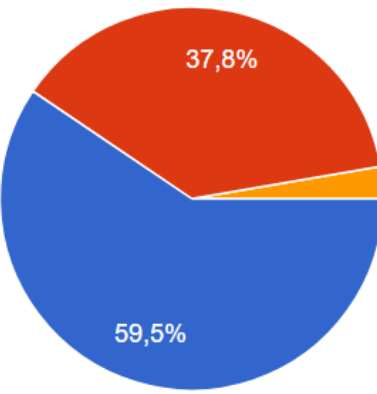

$$
\begin{aligned}
& \text { Branco(a) } \\
& \text { Pardo(a) } \\
& \text { Negro(a) } \\
& \text { Indígena } \\
& \text { Oriental }
\end{aligned}
$$

\section{COR AUTODECLARADA}

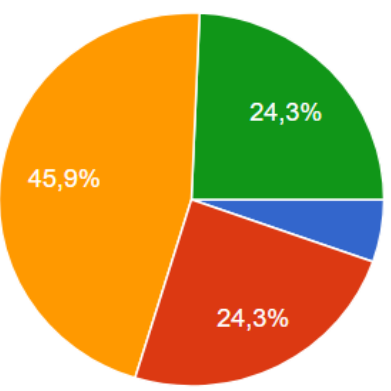

Até 1

De 1 a 3

De 3 a 5

Mais de 5

FAIXA SALARIAL DA FAMÍLIA

(SALÁRIO MÍNIMO R\$ 937,00)

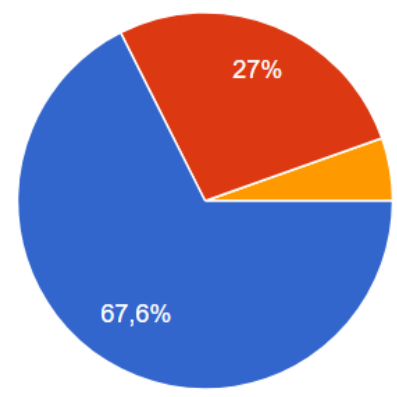

- Ensino Público

Ensino Privado

Ensino Técnico

FORMAÇÃO NO ENSINO MÉDIO, EM SUA MAIORIA

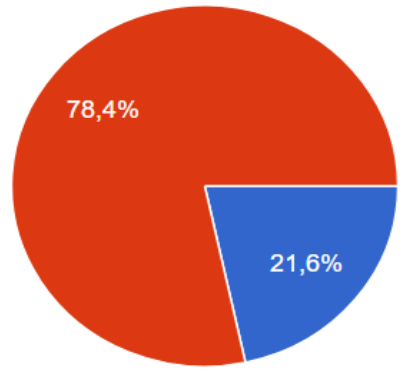

Universidade Pública

Universidade Privada

\section{ACESSO AO ENSINO SUPERIOR}

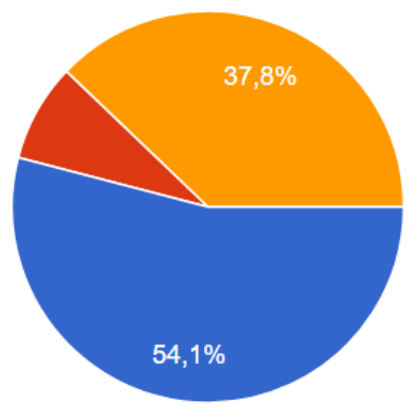




\section{Referências bibliográficas}

ALISSON, Eliton. "A grande massa de estudantes que concluem o ensino médio em escolas públicas não considera o ingresso em universidades públicas", diz Marcelo Knobel. Ensino Superior Unicamp, Campinas, 07 Fev. 2014. Disponível em: https://www.revistaensinosuperior.gr.unicamp.br/reportagens/a-grande-massa-de-estudantesque-concluem-o-ensino-medio-em-escolas-publicas-nao-considera-o-ingresso-emuniversidades-publicas-diz-marcelo-knobel >. Acesso em: 05 de Abril de 2017.

ALMEIDA, Wilson Mesquita de. Estudantes com desvantagens econômicas e educacionais e fruição da universidade. Caderno Crh, [s.1.], v. 20, n. 49, p.35-46, abr. 2007. FapUNIFESP (SciELO).

ANDRADE, CIBELE YAHN. Acesso ao ensino superior no Brasil: equidade e desigualdade social. Revista Ensino Superior Unicamp, Campinas, nº6 , 2012.

BARROS, Aparecida da Silva Xavier. Expansão da educação superior no Brasil: limites e possibilidades. Educ. Soc, Campinas, v. 36, n. 131, p.361-390, jun. 2015.

Dados sobre porcentagem de jovens no Ensino Superior, relacionado com renda familiar, etnia e escolaridade: PNAD/IBGE (2009). Disponível em: < ftp://ftp.ibge.gov.br/Indicadores_Sociais/Sintese_de_Indicadores_Sociais_2008/Tabelas/> . Acesso em: 05 de Abril de 2017.

Dados referentes à porcentagem de estudantes em Universidades Federais - Portal do MEC (2015). Disponível em: < http://portal.mec.gov.br . Acesso em: 05 de Abril de 2017.

NCES. Digest of Education Statistics 2010. 2010. Disponível em: http://nces.ed.gov/programs/digest/d10/tables/dt10_406.asp >. Acesso em: 05 de Abril de 2017. 